\title{
The quality of education in times of new National Curriculum Parameters
}

\author{
Edlamar Kátia Adamy', Elizabeth Teixeira"
}

'Nurse. PhD in Nursing. Adjunct Professor at the Universidade Estadual de Santa Catarina. Director of Education at the ABEn Nacional, Admnistration from 2018 to 2019. Florianópolis, Santa Catarina, Brazil. "Nurse. PhD in Sciences. Professor at the Centro Universitário Luterano de Manaus and at the Universidade do

Estado do Amazonas. Director of Education at the ABEn Nacional, Admnistration from 2016 to 2017. Manaus, Amazonas, Brazil.

\section{How to cite this article:}

Adamy EK, Teixeira E. The quality of education in times of new National Curriculum Parameters. Rev Bras Enferm [Internet]. 2018;71(Suppl 4):1485-6. [Thematic Issue: Education and teaching in Nursing] DOI: http://dx.doi.org/10.1590/0034-7167-201871sup401

The semantic impossibility of delimiting accurately the term "quality" challenges us. When one thinks of quality, it is common to ask questions related to the processes themselves or to the results achieved with emphasis on the satisfaction of those who participated in such processes. Thus, "quality" refers to the skills to carry out successful processes and generate satisfactory products.

Regarding the quality of education, a tension is pointed between formal quality, which is related to the competence of doing; and the political quality, related to the competence of doing and making history ${ }^{(1)}$. From these premises, an educational process, with formal quality, does not necessarily increase the autonomy and protagonism in the students. In order to attain political quality, the educational process will have to go beyond formal quality and to empower students with the perspective of "being" rather than of "having".

Still with regard to the quality of education, another tension pointed out is between quantity and quality. In our view, it makes sense to assert that "every qualitative claim also goes through quantity"(1). It is hoped that the training process is not limited to reaching quantitative indicators, but also has targets other indicators, which corroborates the assertion that quality points to the intensity and depth ${ }^{(1)}$.

Another perspective that challenges us, when it comes to the quality of education, is the inseparability between the political and the epistemological dimensions between theory and practice. For the sociologist, Boaventura de Sousa Santos, "there will be no social justice without cognitive justice"(2). The author affirms that cognitive justice requires such indissociability and for this we must develop emancipatory educational projects, with a view to uplifting education. Like the author, we believe that it is possible to think of different intensities and densities of social processes. And so, both in democracy and in education must be radicalized, we must overcome hegemonic forms in favor of counter-hegemonic forms ${ }^{(2)}$.

When we lived the collective and participative construction of the draft National Curriculum Parameters for nursing undergraduate courses (Nurs-NCP), a process carried out by the Associação Brasileira de Enfermagem$A B E n$ (Brazilian Nursing Association), we were able to reflect, during the forums, on the discussions about what to change, what to include, what to remove and what to keep from many of the tensions announced here, but we believe that the final proposal of the draft has a high intensity of counter-hegemonic forms, translated with competences by areas of training that raise new centralities (of the process on the product, the student in relation to the professor and the training evaluation on training, for example).

The quality of education aimed at undergraduate nursing courses, in times of new Nurs-NCP presupposes that the training is compatible with the constitutional and international references of health promotion and that the graduation of the courses can act with quality, effectiveness and resolution in the Brazilian Unified Health System (SUS).

At this moment, there is a proposal of transformation of the Nursing training, considering the assumptions of the new NCP draft, which aims to train nurses capable of teaching, knowing, classifying, analyzing, commenting, 
speaking, making analogies, registering, making diagnoses, making generalizations, undertaking among other competences that can assure the training of professionals with autonomy, discernment and proactivity, to assure the integrality of care in the Health Care of individuals, family and community.

The frameworks of the proposal point to pedagogical projects with theoretical references in the fields of education, public and collective health, and social and political theory that can guide and justify the proposed principles and guidelines, as well as historical, political, social and cultural references on health practices, nursing, their professionalization and their class entities.

Finally, the quality of the education that is aimed requires the involvement of the different actors that integrate the training process, in a perspective in which the sought educational dimension contributes significantly in the construction of a politicized society, potentializing the human development. In this sense, it is imperative that pedagogical projects comply with Brazilian legislation, involved in pedagogical processes for the training of future nurses committed to taking up the challenges of the profession in a reflective and transforming perspective of society.

\section{REFERENCES}

1. Demo P. Qualidade da educação. São Paulo: Papirus; 2015.

2. Santos BS. A difícil democracia. São Paulo: Boitempo; 2016. 